\title{
Effect of Different Sintering Additives on the Microstructure, Phase Compositions and Mechanical Properties of Si3N4/SiC Ceramics
}

\section{Ying Qin}

Beijing university of chemiacl technology

Hailing Yang

university of Jinan

Qinggang Li ( $\sim$ mse_liqg@ujn.edu.cn )

University of Jinan

\section{Zhi Wang}

University of Jinan

Hao Wu

University of Jinan

Junyan Wu

Jinan University Institute for Economic and Social Research

Xin Cheng

University of Jinan

\section{Rapid Communication}

Keywords: Silicon nitride (Si3N4); Silicon carbide (SiC); Sintering aids; Composite ceramics; Mechanical properties

Posted Date: August 12th, 2020

DOI: https://doi.org/10.21203/rs.3.rs-53947/v1

License: (a) (1) This work is licensed under a Creative Commons Attribution 4.0 International License. Read Full License 


\section{Abstract}

$\mathrm{Y}_{2} \mathrm{O}_{3}$ and $\mathrm{CeO}_{2}$ were chosen as additives to investigate the effect of different additives on the microstructure, composition of phases and mechanical properties of $\mathrm{Si}_{3} \mathrm{~N}_{4} / \mathrm{SiC}$ ceramics using pressureless sintering. $\mathrm{Si}_{3} \mathrm{~N}_{4} / \mathrm{SiC}$ ceramic without additives had a high density, while after adding $\mathrm{Y}_{2} \mathrm{O}_{3}$ and $\mathrm{CeO}_{2}$, the density and flexural strength of $\mathrm{Si}_{3} \mathrm{~N}_{4} / \mathrm{SiC}$ ceramics were significantly decreased due to the increase of porosity. The main phase compositions of samples were $\beta-\mathrm{Si}_{3} \mathrm{~N}_{4}$ and $\mathrm{SiC}$. Moreover, the liquid phases $\mathrm{Y}$-Si-O-N and Ce-Si-O-N were observed after adding $\mathrm{Y}_{2} \mathrm{O}_{3}$ and $\mathrm{CeO}_{2}$ respectively. It also indicated that for $\mathrm{Si}_{3} \mathrm{~N}_{4} / \mathrm{SiC}$ composite ceramics, the high aspect ratio $\beta-\mathrm{Si}_{3} \mathrm{~N}_{4}$ overlapped with each other and closely bonded with glass phase could improve flexure strength effectively. Besides, the SiC crystal grains mainly existed in grain boundary, which could inhibit the secondary recrystallization to avoid that the decrease of flexural strength caused by the overgrowth of $\beta-\mathrm{Si}_{3} \mathrm{~N}_{4}$ grains.

\section{Introduction}

Silicon nitride $\left(\mathrm{Si}_{3} \mathrm{~N}_{4}\right)$ ceramics have been widely applied in modern industry due to its excellent properties including thermal shock resistance, outstanding anti-corrosion and good wear resistance [1-3]. However, the shortcomings of the ceramics such as brittleness, unworkableness and high sensitivity to internal flaws of materials are the main hindrances to its applications $[1,3,4]$. It has been revealed that adding second phase $\left(\mathrm{TiC}, \mathrm{TiO}_{2}, \mathrm{SiC}, \mathrm{BN}\right.$, etc.) with high hardness and chemical resistance, as the reinforcing phase, could improve the properties of ceramics, such as flexural strength, fracture toughness and creep resistance. For example, silicon carbide $(\mathrm{SiC})$ as reinforcing phase includes whiskers and particles [1, 8, 9]. Kai and Yang, et al. [1] obtained the $\mathrm{Si}_{3} \mathrm{~N}_{4} / \mathrm{SiC}$ composite ceramics with high density and excellent mechanical properties by using the $\mathrm{SiC}$ whiskers as a reinforcing phase in $\mathrm{Si}_{3} \mathrm{~N}_{4}$ matrix. Moreover, many researchers have reported that the $\mathrm{SiC}$ nanoparticles were widespread on the grain boundary. The phenonmen has caused interlocking of neighboring $\mathrm{Si}_{3} \mathrm{~N}_{4}$ grains and impede grainboundary sliding, therefore, the hardness, strength and high-temperature properties such as creep behavior of ceramics had been improved [9-11]. In order to industrilise $\mathrm{Si}_{3} \mathrm{~N}_{4} / \mathrm{SiC}$ ceramics, pressureless sintering was selected as a possible method because it was practical to control the size and shape of the product along with temperature schedule [12].

$\mathrm{Si}_{3} \mathrm{~N}_{4}$ and $\mathrm{SiC}$ belong to covalent compounds. Both the covalent bonding $\mathrm{Si}-\mathrm{N}$ and $\mathrm{Si}-\mathrm{C}$ are so strong, and it is difficult to sinter for $\mathrm{Si}_{3} \mathrm{~N}_{4} / \mathrm{SiC}$ ceramics since the sintering temperature is very high $[12,13]$. The oxides are always added to ceramics as sintering additives to promote the process of liquid-phase sintering by forming eutectic liquids at the low sintering temperature. The liquid-phase finally could be reserved as glassy or partially crystalline after cooling, and it usually locates in the junctions of three or two grains [14, 15]. The common sintering additives including $\mathrm{MgO}, \mathrm{Y}_{2} \mathrm{O}_{3}, \mathrm{Yb}_{2} \mathrm{O}_{3}, \mathrm{Al}_{2} \mathrm{O}_{3}, \mathrm{CeO}_{2}$ and so on have been reported [12-16]. In addition, different types and quantities of additives have different effects on the materials. Lojanová and Tatarko $[10,17,18]$, et al. investigated the effects of different rare-earth 
oxides $\mathrm{RE}_{2} \mathrm{O}_{3}\left(\mathrm{RE}=\mathrm{La}, \mathrm{Nd}\right.$, Lu, etc.) on the bending strength and microstructure of $\mathrm{Si}_{3} \mathrm{~N}_{4}-\mathrm{SiC}$ and $\mathrm{Si}_{3} \mathrm{~N}_{4}$ nanocomposites, and it also analyzed the role of $\mathrm{SiC}$ grains inter the matrix. It indicated that the additives and surfaces oxidation layer could form the liquid-phase showing different the viscosity, which influenced the mechanical properties of ceramics and the location of $\mathrm{SiC}$ grains. $\mathrm{Y}_{2} \mathrm{O}_{3}$ and $\mathrm{CeO}_{2}$ have been successfully used as sintering additives for $\mathrm{Si}_{3} \mathrm{~N}_{4}$. The density and bending strength of the materials were improved obviously within certain range of contents $[13,19]$.

In this study, in order to investigate the effect of both $\mathrm{SiC}$ and rare-earth oxides on mechanical properties of $\mathrm{Si}_{3} \mathrm{~N}_{4} / \mathrm{SiC}$ composite ceramics, using $\mathrm{Si}_{3} \mathrm{~N}_{4}$ and $\mathrm{SiC}$ particles as raw materials, $3 \mathrm{wt}$ \% rare earth oxides $\mathrm{Y}_{2} \mathrm{O}_{3}$ and $\mathrm{CeO}_{2}$ as additives respectively to prepare samples by pressureless sintering method.

Furthermore, the microstructure and phase compositions were also analyzed, which might provide evidences to reveal the relationships between the sintering additives and the mechanical properties.

\section{Materials And Method}

\subsection{Sample Preparation}

$\mathrm{Si}_{3} \mathrm{~N}_{4}$ powders (a-phase $92 \%$, $\beta$-phase $8 \%$, Shanghai Shuitian Technology Co., LTD., Shanghai, China, Chemical Composition and Content of $\mathrm{Si}_{3} \mathrm{~N}_{4}$ were shown in Table 1) were used as the matrix materials and SiC powders (average particle size $5 \mu \mathrm{m}$, purity $>99.9 \%$,Shanghai ST-Nano Technology Co. Ltd., China) were used as reinforcement in this study. The proportion of $\mathrm{Si}_{3} \mathrm{~N}_{4}$ and $\mathrm{SiC}$ is $95: 5$. Rare earth oxides $\mathrm{Y}_{2} \mathrm{O}_{3}$ (purity $>99.95 \%$, Ganzhou Jin Chengyuan new materials Co., LTD., Jiangxi, China) and $\mathrm{CeO}_{2}$ (purity $>99.95 \%$ ) were added as sintering additives respectively, both the content of $\mathrm{Y}_{2} \mathrm{O}_{3}$ and $\mathrm{CeO}_{2}$ is 3 wt. \%. The detailed information is shown in Table 2. Figure 1 showed the XRD pattern (Fig. 1(a)) and SEM micrograph (Fig. 1(b)) of $\mathrm{Si}_{3} \mathrm{~N}_{4}$ powders, and the Fig. 1 indicated that the main crystal phase of particles was $\mathrm{a}-\mathrm{Si}_{3} \mathrm{~N}_{4}$, and some of the powders were agglomerating. SEM image and grain diameter distribution map of SiC powders were shown in Fig. 2. Demonstrate show that the agglomeration of $\mathrm{SiC}$ particles was observed (Fig. 2(a)), and the average particulate diameter was around $5 \mu \mathrm{m}$. Rare-earth oxides $\mathrm{Y}_{2} \mathrm{O}_{3}$ and $\mathrm{CeO}_{2}$ particles were spherical with obvious agglomeration as shown in Fig. $3((\mathrm{a})$ and (b)), and both of them had particle sizes less than $50 \mathrm{~nm}$. The mixtures were ball-milled in ethanol for $12 \mathrm{~h}$, followed by drying for $15 \mathrm{~h}$ at $85^{\circ} \mathrm{C}$, and then sieving through 250 mesh. Afterward, the green body was formed by the cold isostatic pressing method under $200 \mathrm{MPa}$ for $2 \mathrm{~min}$. Then under the nitrogen atmosphere, materials were sintering at $1950{ }^{\circ} \mathrm{C}$ for $1.5 \mathrm{~h}$ without pressure.

Table 1

Chemical composition and content of silicon nitride.

\begin{tabular}{|lllllllll|}
\hline material & a phase & $\boldsymbol{\beta}$ phase & $\mathbf{F e}$ & $\mathbf{A l}$ & $\mathbf{0}$ & $\mathbf{C}$ & $\mathbf{S i}$ & BET \\
\hline $\mathrm{Si}_{3} \mathrm{~N}_{4}$ & 92 & 8 & 0.04 & 0.03 & $1.1-1.4$ & $0.18-0.25$ & $0.1-0.2$ & $10-10.9 \mathrm{~m}^{2} / \mathrm{g}$ \\
\hline
\end{tabular}


Table 2

Designations and corresponding composition of the samples.

\begin{tabular}{|llll|}
\hline Sample & \multicolumn{3}{l}{ Component concentration (wt.\%) } \\
\cline { 2 - 4 } & $\mathrm{Si}_{3} \mathrm{~N}_{\mathbf{4}}: \mathrm{SiC}$ & $\mathrm{Y}_{\mathbf{2}} \mathrm{O}_{\mathbf{3}}$ & $\mathrm{CeO}_{2}$ \\
\hline $\mathrm{SC}$ & $95: 5$ & 0 & 0 \\
$\mathrm{SCY}$ & $95: 5$ & 3 & 0 \\
\hline $\mathrm{SCC}$ & $95: 5$ & 0 & 3 \\
\hline
\end{tabular}

\subsection{Characterization}

The densities $(\rho)$ and apparent porosity $(P)$ of samples were measured by the Archimedes method. The flexure strength via the three-point bending test using electromechanical universal testing machine (CMT5150, China) and the samples were machined into rectangle bars with a size of $3.0 \mathrm{~mm} \times 4.0 \mathrm{~mm} \times$ $36.0 \mathrm{~mm}$; the support distance of $30.0 \mathrm{~mm}$ and a cross-head speed of $0.5 \mathrm{~mm} / \mathrm{min}$ were used. After the three -point bending test, the microstructure on the fracture surface of the samples was observed by Scanning Electron Microscope (SEM, JSM-6510LV, JEOL, Tokyo, Japan). Crystalline phases of raw materials and sintered samples were identified by X-ray diffractometry (XRD, D8-ADVANCE, Bruker, Karlsruhe, Germany) with $\mathrm{Cu}_{\mathrm{a}}$ radiation. In addition, Transmission Electron Microscope (TEM, JEM2100, JEOL, Tokyo, Japan) was used to further determine the microstructure, particle morphology and composition of the materials.

\section{Results And Discussion}

\subsection{Densification behavior and mechanical properties}

Figure 4 was the macroscopic morphology of $\mathrm{Si}_{3} \mathrm{~N}_{4} / \mathrm{SiC}$ composite ceramics after sintering at $1950{ }^{\circ} \mathrm{C}$. It is obvious that the color of samples had been changed; the sample SC was shown black, while the sample SCY and SCC were shown gray-white after adding $\mathrm{Y}_{2} \mathrm{O}_{3}$ and $\mathrm{CeO}_{2}$. It is widely known that $\mathrm{Y}_{2} \mathrm{O}_{3}$ and $\mathrm{CeO}_{2}$ are common sintering additives, which could form the eutectic solution with $\mathrm{Si}_{3} \mathrm{~N}_{4}$ and $\mathrm{SiC}$, the difference of absorption spectra for different materials results in different colors of the sample surface. The main properties of the samples were shown in Table 3, and Fig. 5 was drawn to describe the relationship between the performances clearly. From Fig. 5, it was not difficult to see that sample SC without admixture had higher density after sintering, and the porosity of SC was less than 0.5 percent. It was indicating that this sample had been fully sintered. With the sintering process, the pores of SC samples could be moved following the migration of grain boundary and then discharged from the body through the grain boundary, resulting in the densification of the material. 
However, after adding $\mathrm{Y}_{2} \mathrm{O}_{3}$ and $\mathrm{CeO}_{2}$, the porosities of SCY and SCC were increased significantly resulting in lower densities and mechanical properties, which were contrary to expectations. Generally, sintering additives promote liquid phase sintering through dissolution and precipitation mechanism [17]. Besides, according to previous reports, the type and content of sintering additives affect the amount and viscosity of the liquid, which in turn affect densification, grain coarsening and mechanical properties of $\mathrm{Si}_{3} \mathrm{~N}_{4}$ as well as influence the stability of $\mathrm{SiC}$ [1]. Therefore, the relative density reduction might be due to that the glass phase formed after adding the sintering additives. The glass phase is conducive to the growth of $\mathrm{Si}_{3} \mathrm{~N}_{4}$ grains and tends to form larger grains, which hinder the flow of liquid phase. When the porosity is high in ceramics, it will become the main factor to reduce the flexural strength since the increase of defects. The additive loss (bloating) during prolonged annealing at high temperatures caused the increase of the pores quantity $[6,20]$. And another possibility was that parts of $\mathrm{Si}_{3} \mathrm{~N}_{4}$ grains were decomposed at high temperature without pressure, reducing the densification of the material and increasing the porosity. Furthermore, the densification behavior and mechanical properties of SCY and SCC ceramics could be influenced by sintering temperature, sintering time and the addition amount of the additives, which are the research targets in the future.

Table 3

Mechanical properties of Si3N4/SiC composite ceramics

\begin{tabular}{|lllll|}
\hline Samples & additives(\%) & Density $(\boldsymbol{\rho})\left(\mathrm{g} / \mathrm{cm}^{3}\right)$ & Porosity $(\mathrm{P})$ & Flexure strength(MPa) \\
\hline SC & & 3.0485 & 0.4192 & 329.11 \\
SCY & $\mathrm{Y}_{2} \mathrm{O}_{3}$ & 2.2923 & 21.33 & 170.79 \\
SCC & $\mathrm{CeO}_{2}$ & 2.2666 & 22.75 & 143.71 \\
\hline
\end{tabular}

It can be seen that the trend of porosity in the materials was converse with the flexure strength (Fig. 5), which is consistent with other studies $[19,21]$. The ceramic with lower porosity indicated that there were fewer internal defects and more grain boundaries, which explained the high strength of the material.

Therefore, the flexure strength of SC was significantly higher than SCY and SCC. It can be concluded that the additives $\mathrm{Y}_{2} \mathrm{O}_{3}$ and $\mathrm{CeO}_{2}$ were beneficial to improve the porosity of materials. The factors influencing the strength could be analyzed from the internal structure and the crystal phase composition of materials. The action mechanisms for flexure strength will be described in more detail below.

\subsection{Phase transformation and microstructure}

\subsubsection{SEM and XRD analysis}

The microstructure of the fracture surface of $\mathrm{Si}_{3} \mathrm{~N}_{4} / \mathrm{SiC}$ composite materials was shown in Fig. 6. It can be seen that the fracture surface of SC without any additives was very dense and had few pores. Rod-like $\beta-\mathrm{Si}_{3} \mathrm{~N}_{4}$ grains and a small amount of glass phase could be observed from Fig. 6 (a) and (b). The interweave of $\beta-\mathrm{Si}_{3} \mathrm{~N}_{4}$ grains and glass phase effectively improved the mechanical properties of 
materials. In addition, previous research has shown that the overlapping structure of $\beta-\mathrm{Si}_{3} \mathrm{~N}_{4}$ crystals with high aspect ratio, by bridging and pullout, is beneficial to improve the strength of materials, while the oversized grains with high width have a negative effect on the strength [2]. However, adding SiC dispersion particles could inhibit the secondary recrystallization of $\beta-\mathrm{Si}_{3} \mathrm{~N}_{4}$ crystals [9]. Thus, the size of $\beta-\mathrm{Si}_{3} \mathrm{~N}_{4}$ grains would not be too large, so as to decrease the mechanical properties. That may aplain why sample SC had the high flexure strength. For SCY and SCC, it can be seen from Fig. 6 that the density decreased, the porosity increased obviously, and the structure was loose, which explained why the flexure strength decreased after adding the sintering aids. In addition, short columnar $\beta-\mathrm{Si}_{3} \mathrm{~N}_{4}$ grains and glass phases were observed in these samples, and the pores were mainly formed by the overlapping of $\beta-\mathrm{Si}_{3} \mathrm{~N}_{4}$. It could also be found that the flexure strength of SCY was slightly higher than SCC. For all the samples, the fracture surface of the samples displayed the intergranular fracture as a whole. The holes left by rodlike $\beta-\mathrm{Si}_{3} \mathrm{~N}_{4}$ crystals after fracture could be seen clearly in Fig. 6, particularly in SCC. Besides, the phenomenon that the crystal grains were pulled out from the matrix was also observed in SC and SCY. Therefore, the strengthening mechanism of composites could be attributed to intergranular fracture and grain pullout.

The phase composition of the samples was shown in Fig. 7. The main phase compositions of the composite materials were $\beta-\mathrm{Si}_{3} \mathrm{~N}_{4}$ and $\mathrm{SiC}$, which is consistent with the SEM (Fig. 6). Besides, a-Si ${ }_{3} \mathrm{~N}_{4}$ crystal phase was not be observed, indicating that the $\alpha-\beta$ phase transformation was complete at high temperature. For sample $\mathrm{SCY}$ and $\mathrm{SCC}$, the sintering additives $\mathrm{Y}_{2} \mathrm{O}_{3}$ and $\mathrm{CeO}_{2}$ will react with the $\mathrm{SiO}_{2}$ oxide film formed at the particle surface at high temperature so that the ternary system of $\mathrm{Si}_{3} \mathrm{~N}_{4}-\mathrm{Y}_{2} \mathrm{O}_{3^{-}}$$\mathrm{SiO}_{2}$ and $\mathrm{Si}_{3} \mathrm{~N}_{4}-\mathrm{CeO}_{2}-\mathrm{SiO}_{2}$ formed. The liquid phases $\mathrm{Y}$-Si-O-N and Ce-Si-O-N were generated at last as shown in Fig. 7, which could reduce the sintering temperature of the materials and promote the $\alpha-\beta$ phase transformation as previously stated. Besides, the $\mathrm{Y}_{2} \mathrm{SiO}_{7}$ phase was also observed in sample SCY.

\subsubsection{TEM analysis}

TEM with higher resolution microscope was used on sample SCC to fully analyze the crystal phase composition and structure of it, as shown in Fig. 8. Many pores and $\beta-\mathrm{Si}_{3} \mathrm{~N}_{4}$ grains with a low aspect ratio were observed in Fig. 8(a). Moreover, there were many internal defects in sample SCC, which may be formed by the decomposition of $\mathrm{Si}_{3} \mathrm{~N}_{4}$ at the high temperature without external force, or by the failure of energy release during the rapid cooling. This verified the conclusion which mentioned before and further analyzed the reason of why the bending strength decreased after adding $\mathrm{CeO}_{2}$. As shown in the Fig. 8(b), the interplanar spacing was $0.62 \mathrm{~nm}$ proved that the phase was $\beta-\mathrm{Si}_{3} \mathrm{~N}_{4}$, which was consistent with the results of XRD. The liquid phase (indicated by the arrow in Fig. 8(b)) formed by the $\mathrm{SiO}_{2}$ oxide film of $\mathrm{Si}_{3} \mathrm{~N}_{4}$ surface and sintering aids could be observed clearly, and it was located at the junction of two or more grain phases. Moreover, the SiC grains with irregular shape were identified in the grain boundaries. Many researches have shown that $\mathrm{SiC}$ grains have an inhibitory effect on the secondary recrystallization 
of $\mathrm{Si}_{3} \mathrm{~N}_{4}$ grains and the inhibition effect increases with the increase of the size $[9,11]$. Therefore, the $\beta$ $\mathrm{Si}_{3} \mathrm{~N}_{4}$ grains would not grow too large to reduce the strength of materials.

\section{Conclusions}

The influences of $\mathrm{Y}_{2} \mathrm{O}_{3}$ and $\mathrm{CeO}_{2}$ additives on the mechanical and microstructure of $\mathrm{Si}_{3} \mathrm{~N}_{4} / \mathrm{SiC}$ composite ceramics have been investigated, and the impact of $\mathrm{SiC}$ on the material structure has also been studied. The sample SC obtained by using pressureless sintering without additives had high bending strength and density, while the flexure strength of samples SCY and SCC decreased obviously. It was mainly influenced by the viscosity of the eutectic mixture formed by $\mathrm{Si}_{3} \mathrm{~N}_{4}$, oxides and decomposition of silicon nitride. The main crystal phase of $\mathrm{Si}_{3} \mathrm{~N}_{4} / \mathrm{SiC}$ composite ceramics was $\beta-\mathrm{Si}_{3} \mathrm{~N}_{4}$, which could combine with glass phase closely to improve the flexure strength. In addition, $\mathrm{SiC}$ particles which located in grain boundary could inhibit the secondary recrystallization of the grains effectively, and avoid adverse effects on the strength of materials due to the oversize $\beta-\mathrm{Si}_{3} \mathrm{~N}_{4}$ grains. The influences of additive content and sintering temperature will be research targets in the future.

\section{Declarations}

\section{Acknowledgements}

Authors appreciate the financial supported by the National Natural Science Foundation of China (Grant Nos. 51872118, 51701081), the Key Research and Development Program of Shandong Province (Grant Nos. 2019GGX104077, 2019RKB01018), the Shandong Provincial Natural Science Foundation, (Grant Nos. ZR2018PEM008, ZR2019MEM055). This work was financially supported by National Natural Science Foundation of China (51632003), the Taishan Scholars Program, and the Case-by-Case Project for Top Outstanding Talents of Jinan.

\section{References}

1. Kai W, Yang JM, Shih CJ et al (1992) Effect of sintering additives on the behavior of SiC whiskerreinforced $\mathrm{Si}_{3} \mathrm{~N}_{4}$ composites. J Mater Sci 27:3706-3718

2. Yang JF, Deng ZY, Ohji T (2003) Fabrication and characterisation of porous silicon nitride ceramics using $\mathrm{Yb}_{2} \mathrm{O}_{3}$ as sintering additive. J Eur Ceram Soc 23(2):371-378

3. Tunckan O, Yurdakul $\mathrm{H}$, Turan S (2019) Unveiling the reaction products in heat treated $\mathrm{Si}_{3} \mathrm{~N}_{4}-\mathrm{Ti}$ joined ceramics by transmission electron microscopy. J Adv Cerma 8(4):500-508

4. Li SQ, Huang Y, Wang CA et al (2001) Mechanical properties of $\mathrm{Si}_{3} \mathrm{~N}_{4} / \mathrm{BN}$ fibrous monolithic ceramics at elevated-temperature. J Mater Sci 36:4103-4106

5. Hu HL, Zeng YP, Zuo KH et al (2014) Effect of sintering additive composition on the mechanical and tribological properties of $\mathrm{Si}_{3} \mathrm{~N}_{4} / \mathrm{SiC}$ ceramics. J Inorg Mater 29(8):885-890 
6. Biswas SK, Riley FL (2003) Gas pressure sintering of silicon nitride powder coated with $\mathrm{Al}_{2} \mathrm{O}_{3}$ and $\mathrm{TiO}_{2}$. J Am Ceram Soc 86(2):212-216

7. Chen JJ, Chen JX, Zhang $\mathrm{H}$ et al (2018) Microstructure and mechanical properties of $\mathrm{h}$ $\mathrm{BN} / \mathrm{Yb}_{4} \mathrm{Si}_{2} \mathrm{O}_{7} \mathrm{~N}_{2}$ composites. J Adv Ceram 7(4):317-324

8. Herrmann M, Klemm H, Göbel B et al (1999) $\mathrm{SiC} / \mathrm{Si}_{3} \mathrm{~N}_{4}$ nanocomposites with excellent hightemperature long-term behaviour. Key Eng Mater 161-163:377-380

9. Kašiarová M, Shollock B, Boccaccini A et al (2009) Microstructure and creep behavior of a $\mathrm{Si}_{3} \mathrm{~N}_{4}-\mathrm{SiC}$ micronanocomposite. J Am Ceram Soc 92(2):439-444

10. Lojanová S, Tatarko P, Chlup Z et al (2010) Rare-earth element doped $\mathrm{Si}_{3} \mathrm{~N}_{4} / \mathrm{SiC}$ micro/nanocomposites-RT and HT mechanical properties. J Eur Ceram 30:1931-1944

11. Dusza J, Kovalčík J, Hvizdoš $P$ et al (2004) Creep behavior of a carbon-derived $\mathrm{Si}_{3} \mathrm{~N}_{4} / \mathrm{SiC}$ nanocomposite. J Eur Ceram 24:3307-3315

12. Liang $\mathrm{HQ}$, Yao XM, Zhang JX et al (2014) Low temperature pressureless sintering of a-SiC with $\mathrm{Al}_{2} \mathrm{O}_{3}$ and $\mathrm{CeO}_{2}$ as additives. $\mathrm{J}$ Eur Ceram Soc 34:831-835

13. Jojo N, Shongwe MB, Tshabalala LC et al (2019) Effect of sintering temperature and yttrium composition on the densification, microstructure and mechanical properties of spark plasma sintered silicon nitride ceramics with $\mathrm{Al}_{2} \mathrm{O}_{3}$ and $\mathrm{Y}_{2} \mathrm{O}_{3}$ additives. Silicon 11:2689-2699

14. Kašiarová $M$, Tatarko $P$, Burik $P$ et al (2014) Thermal shock resistance of $\mathrm{Si}_{3} \mathrm{~N}_{4}$ and $\mathrm{Si}_{3} \mathrm{~N}_{4}-\mathrm{SiC}$ ceramics with rare-earth oxide sintering additives. J Eur Ceram Soc 34(14):3301-3308

15. Cinibulk MK, Thomas G, Johnson SM (1992) Fabrication and secondary-phase crystallization of rareearth disilicate-silicon nitride ceramics. J Am Ceram Soc 75(8):2037-2043

16. Li F, Zhou L, Liu JX et al (2018) High-entropy pyrochlores with low thermal conductivity for thermal barrier coating materials. J Adv Ceram 7(4):317-324

17. Tatarko P, Kašiarová M, Dusza J et al (2013) Influence of rare-earth oxide additives on the oxidation resistance of $\mathrm{Si}_{3} \mathrm{~N}_{4}-\mathrm{SiC}$ nanocomposites. J Eur Ceram Soc 33:2259-2268

18. Becher PF, Shibata N, Painter GS et al (2010) Observations on the Influence of Secondary Me Oxide Additives $(\mathrm{Me}=\mathrm{Si}, \mathrm{Al}, \mathrm{Mg})$ on the Microstructural Evolution and Mechanical Behavior of Silicon Nitride Ceramics Containing $\mathrm{RE}_{2} \mathrm{O}_{3}(\mathrm{RE}=\mathrm{La}, \mathrm{Gd}, \mathrm{Lu})$. J Am Ceram Soc 93(2):570-580

19. Yang $\mathrm{HT}$, Gao L, Yuan RZ et al (2001) Effect of $\mathrm{MgO} / \mathrm{CeO}_{2}$ on pressureless sintering of silicon nitride. Mater Chem Phys 69:281-283

20. Hwang SL, Becher PF, Lin HT (1997) Desintering process in the gas pressure sintering of silicon nitride. J Am Ceram Soc 80(2):329-335

21. Lu GQ (1996) Evolution of the pore structure of a ceramic powder compact during sintering. J Mater Process Tech 59:297-302

\section{Figures}




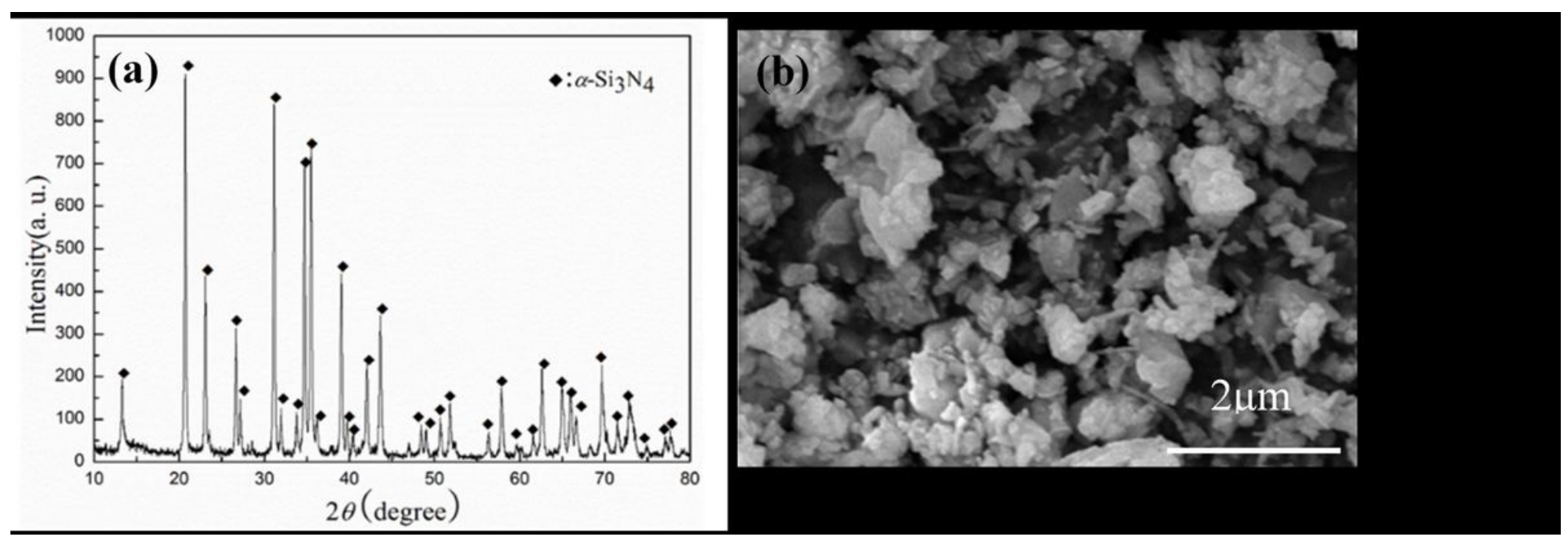

Figure 1

(a) XRD pattern of Si3N4 powders; (b) SEM image of Si3N4 powders.

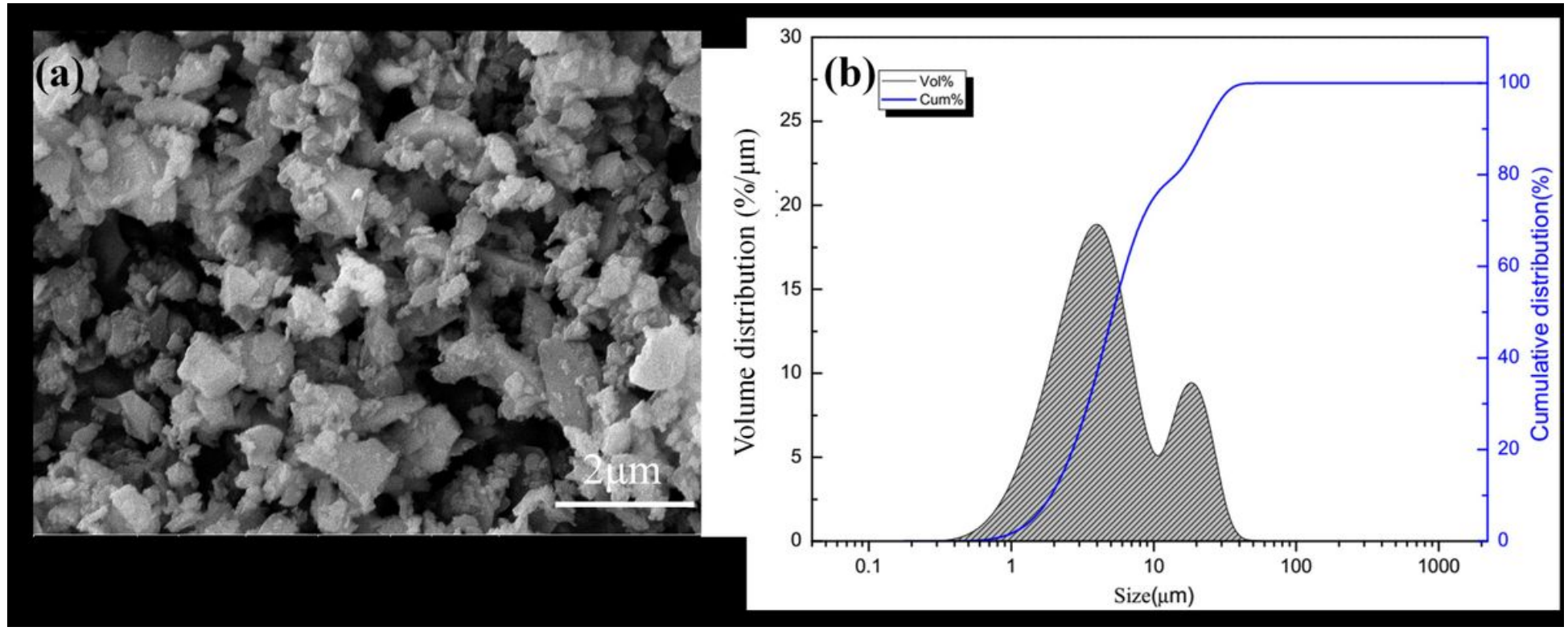

Figure 2

(a) SEM image of SiC powders; (b) Particle size distribution of SiC powders. 

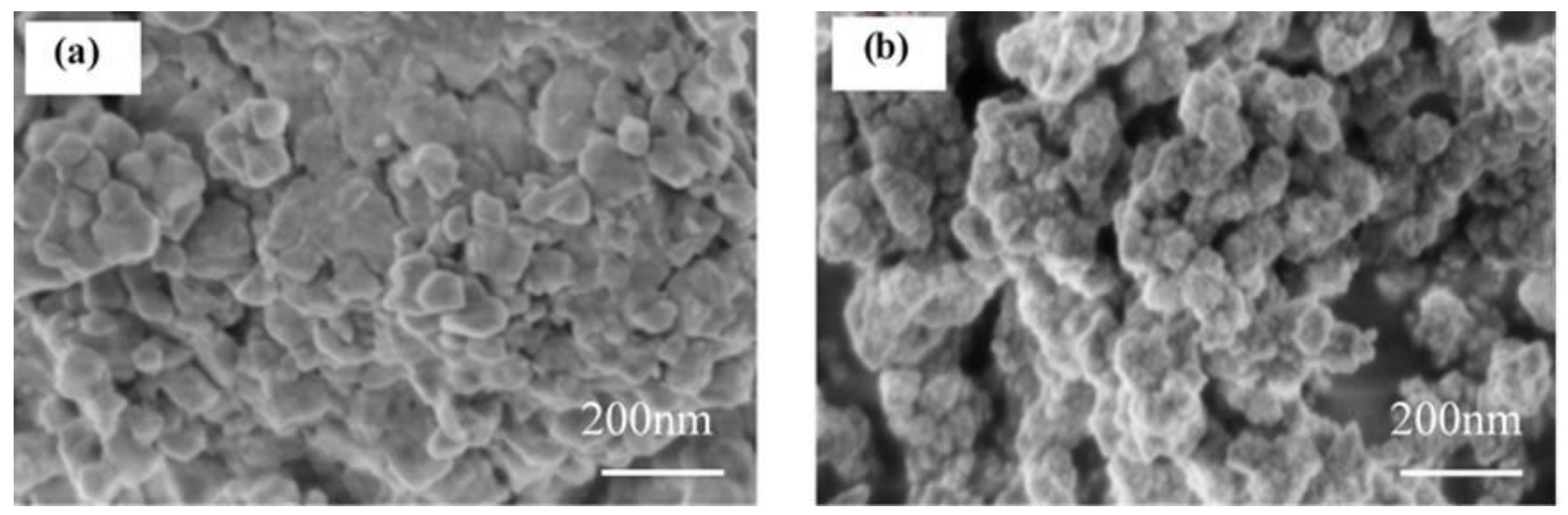

\section{Figure 3}

SEM images of rare earth oxides: (a) Y2O3, (b) CeO2.
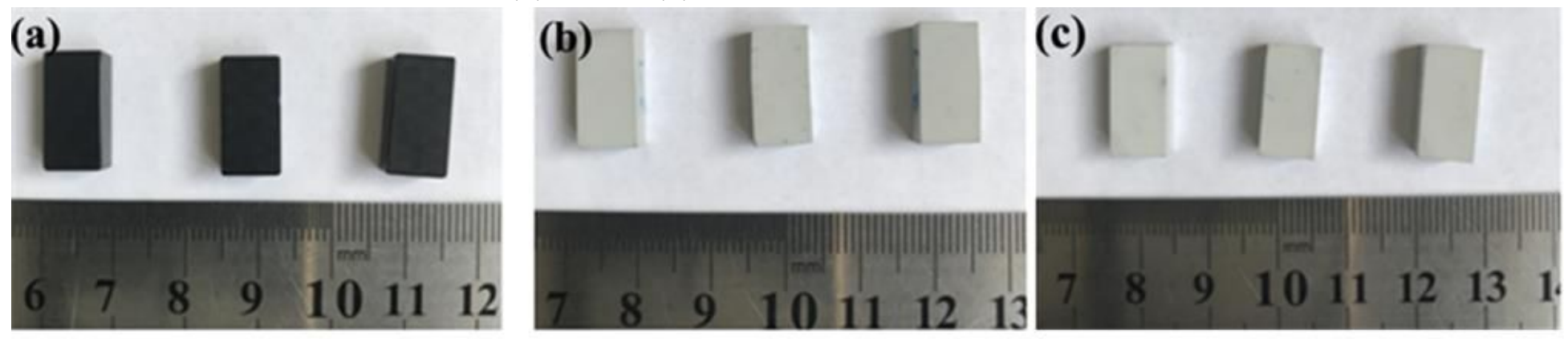

\section{Figure 4}

Macroscopic morphology of sintered samples: (a) SC, (b) SCY, (c) SCC. 


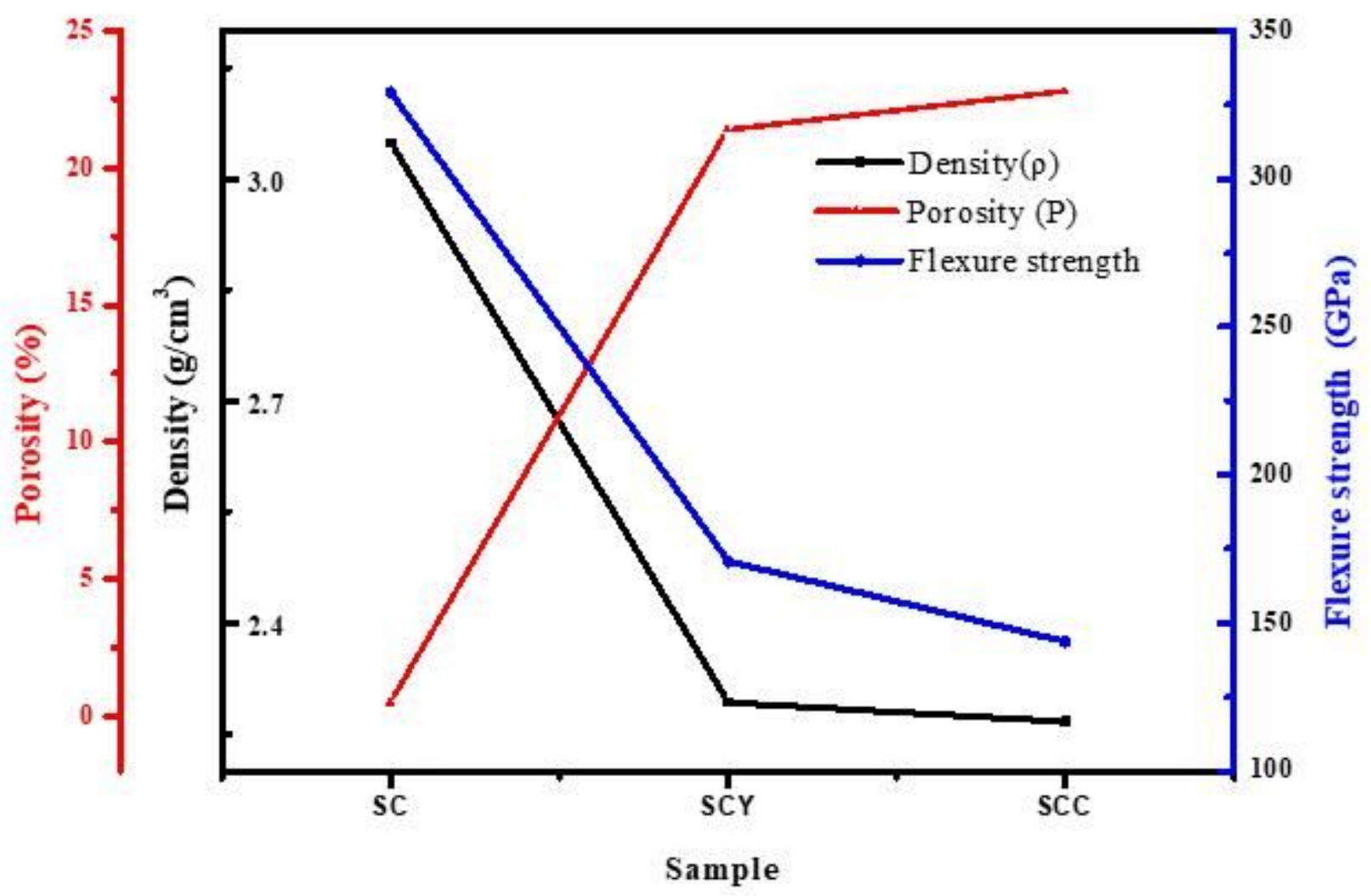

Figure 5

Effect of additives on the density, porosity and flexure strength of composite materials. 

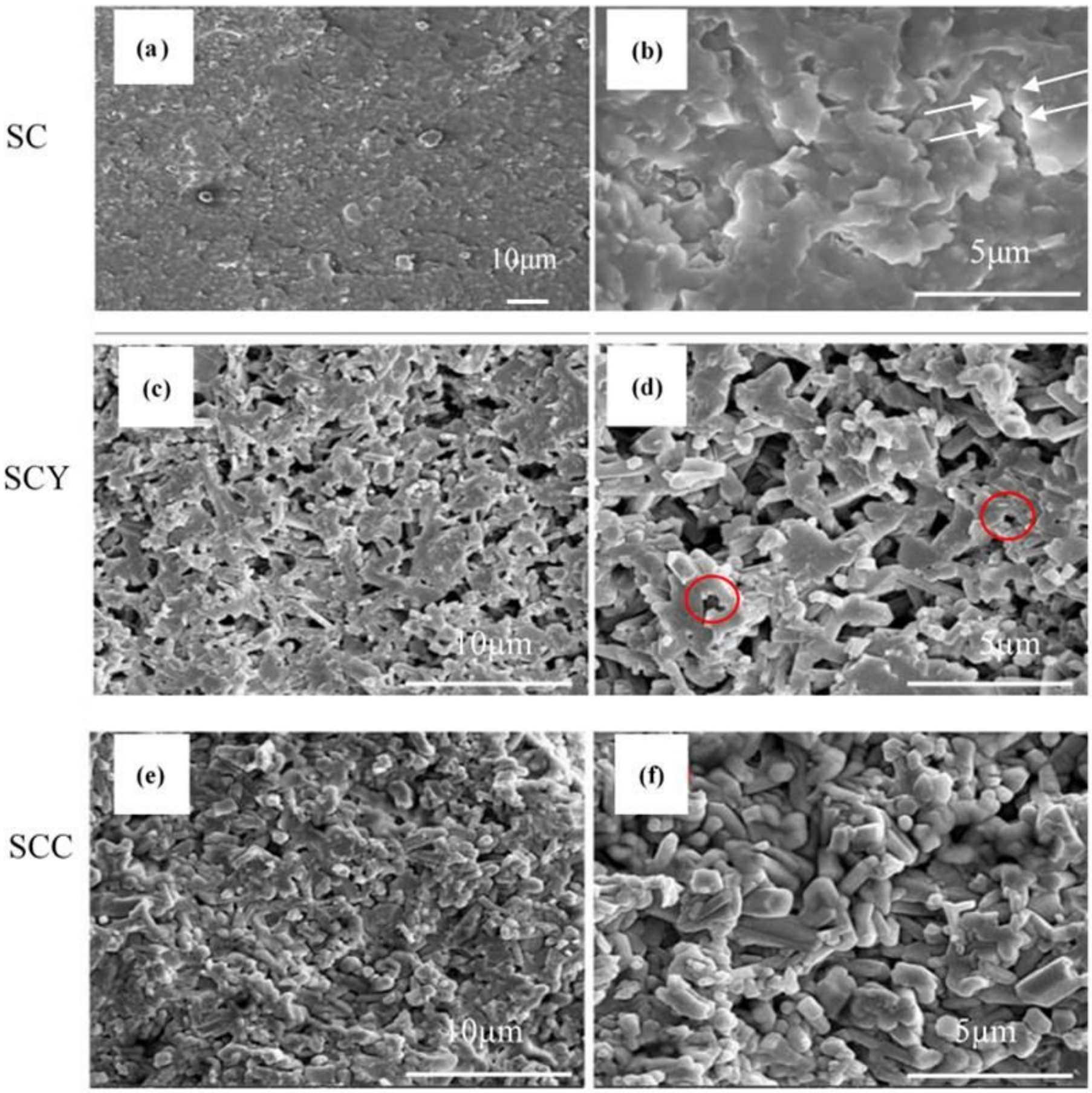

Figure 6

Microstructure of Si3N4/SiC composites cross section. 


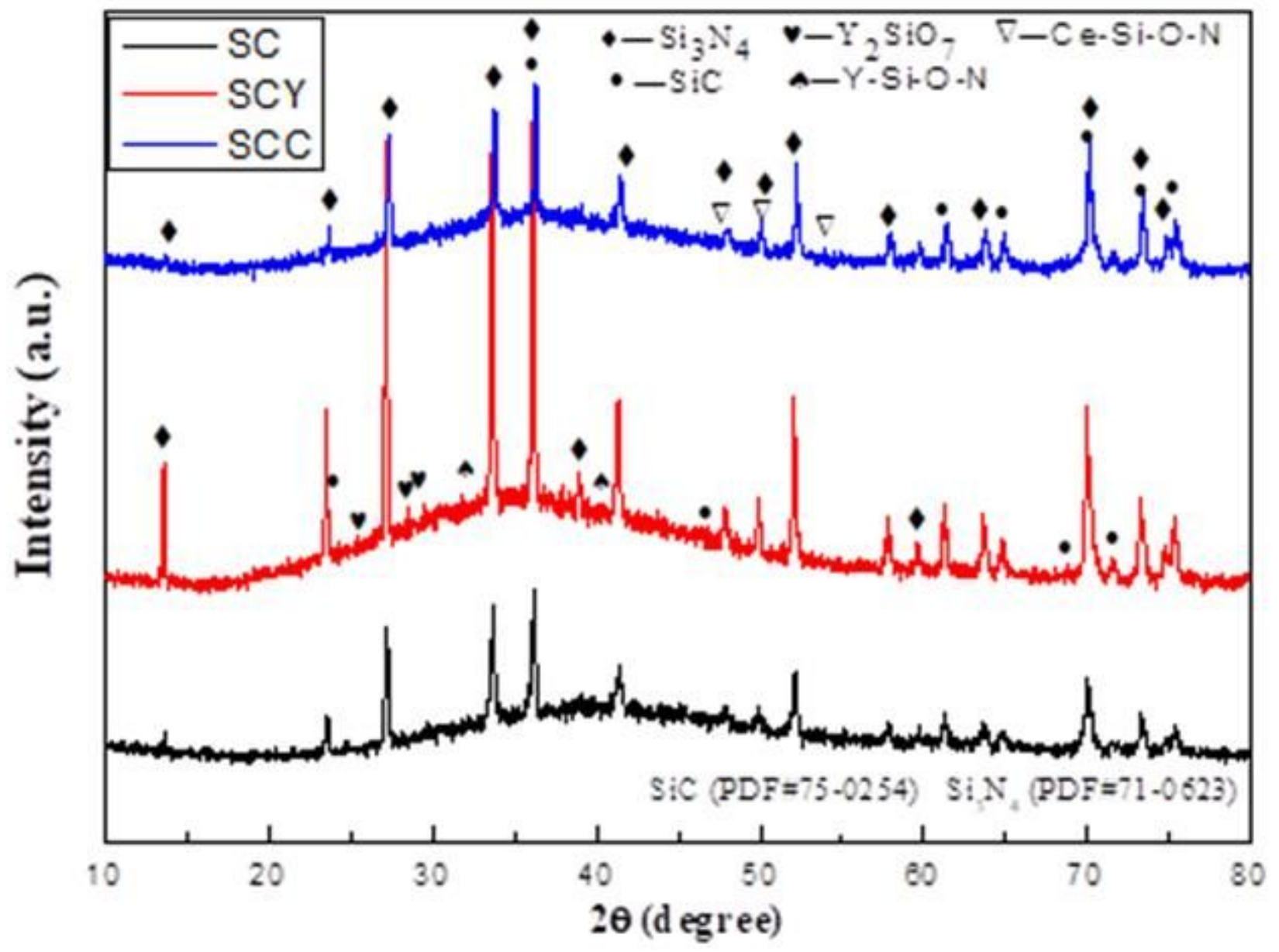

Figure 7

XRD pattern of Si3N4/SiC composite ceramics.

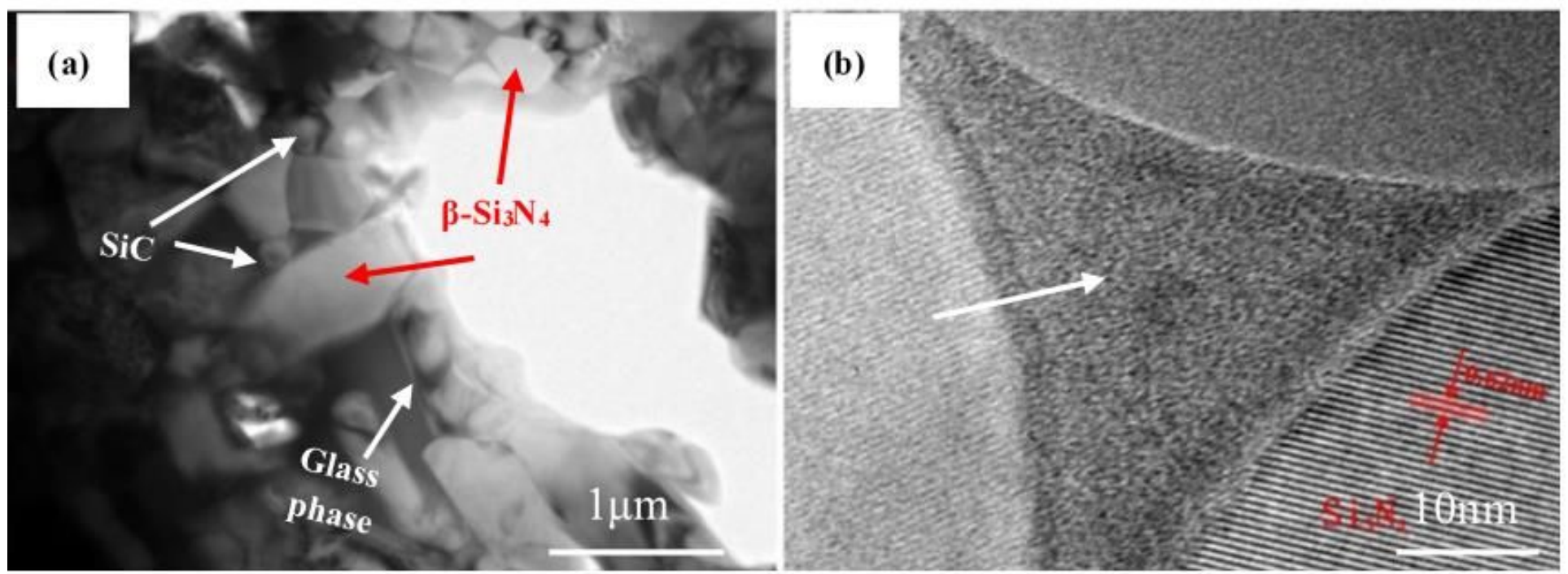

Figure 8

TEM pictures of the sample SCC: (a) TEM image; (b) HRTEM image. 